OPEN ACCESS

Edited by:

Carl E. Stafstrom, Johns Hopkins Medicine,

United States

Reviewed by: Yehezkel Ben-Ari, Neurochlore, France Akira Monij,

Saga University, Japan

*Correspondence:

Jérôme Mairesse

j_mairesse@hotmail.com

these authors have contributed equally to this work.

Specialty section: This article was submitted to

Pediatric Neurology, a section of the journa

Frontiers in Neurology

Received: 24 January 2018 Accepted: 23 March 2018

Published: 13 April 2018

Citation:

Zinni M, Colella M, Batista Novais $A R$, Baud $O$ and Mairesse J (2018) Modulating the Oxytocin System During the Perinatal Period: A New Strategy for Neuroprotection of the Immature Brain?

Front. Neurol. 9:229.

doi: 10.3389/fneur.2018.00229

\section{Modulating the Oxytocin System During the Perinatal Period: A New Strategy for Neuroprotection of the Immature Brain?}

\author{
Manuela Zinni', Marina Colella ${ }^{1}$, Aline Rideau Batista Novais ${ }^{1,2}$, Olivier Baud ${ }^{1,3,4 \dagger}$ \\ and Jérôme Mairesse ${ }^{1,3 * t}$
}

IINSERM U1141 Protect, Paris-Diderot University, Paris, France, ${ }^{2}$ Neonatal Intensive Care Unit, Robert Debré Children's Hospital, Paris, France, ${ }^{3}$ University of Geneva, Geneva, Switzerland, ${ }^{4}$ Division of Neonatology, Geneva Children's Hospital, Geneva, Switzerland

Oxytocin is a neurohypophysal hormone known for its activity during labor and its role in lactation. However, the function of oxytocin (OTX) goes far beyond the peripheral regulation of reproduction, and the central effects of OTX have been extensively investigated, since it has been recognized to influence the learning and memory processes. OTX has also prominent effects on social behavior, anxiety, and autism. Interaction between glucocorticoids, OTX, and maternal behavior may have long-term effects on the developmental program of the developing brain subjected to adverse events during pre and perinatal periods. OTX treatment in humans improves many aspects of social cognition and behavior. Its effects on the hypothalamic-pituitary-adrenal axis and inflammation appear to be of interest in neonates because these properties may confer benefits when the perinatal brain has been subjected to injury. Indeed, early life inflammation and abnormal adrenal response to stress have been associated with an abnormal white matter development. Recent investigations demonstrated that OTX is involved in the modulation of microglial reactivity in the developing brain. This review recapitulates stateof-the art data supporting the hypothesis that the OTX system could be considered as an innovative candidate for neuroprotection, especially in the immature brain.

Keywords: intra-uterine growth restriction, neuro-inflammation, white matter brain injury, oxytocin, microglia, glucocorticosteroid, GABA, maternal behavior

\section{WHITE MATTER INJURY (WMI) FOLLOWING FETAL GROWTH RESTRICTION}

Intrauterine growth restriction (IUGR) is a complication observed in $10 \%$ of the pregnancies (1) and represents the major causes of neonatal mortality and morbidity (2). Placental insufficiency resulting in fetal hypoxia and maternal malnutrition are two identifiable and major causes of IUGR (3). Due to its constant increase in both industrialized and developing countries, where 2.8 million children out of 135 million born in 2010 were born preterm and growth restricted (4), IUGR represents an important public health problem. Indeed, growth-restricted infants showed a higher risk of perinatal morbidity and of neurodevelopmental alteration with long-term cognitive and neurobehavioral handicaps $(5,6)$. Interestingly, studies based on magnetic resonance imaging have clearly evidenced that the cognitive and psychiatric deficits observed (7-9) are correlated to alterations of brain white and gray matter $(7,10,11)$, including altered neural circuitry $(12,13)$. The importance of IUGR in the context of public health economy is further highlighted by the presence of a positive correlation between the 
severity of IUGR and the risk to develop cerebral palsy (14), risk that is 10 - to 30 -fold higher in IUGR babies (15-18).

The mechanisms responsible for the induction of brain injury in preterm infants remain largely elusive and several putative inductor factors have been identified (oxidative stress, excitotoxicity, neuroinflammation) (19). In the hereinafter of this section, we will focus on the role of neuroinflammation and the possible cellular mechanisms responsible for inflammatory-induced brain damage.

Clinical studies showed that abnormal inflammatory responses in the fetus and/or in the neonate can contribute to white matter damage $(20,21)$. These clinical observations are well supported by studies conducted in rodents in which IUGR is not only associated with an abnormal neuroinflammatory response and myelinization defects (22-24), but is also a risk factor for the development of inflammatory-induced brain damage (25).

The brain inflammatory response is orchestrated by crosstalk between microglia and astrocyte (26). In particular, microglia (brain resident macrophage) colonizes the brain during development in two phases: the fetal development (first two trimesters in humans and between embryonic days (EDs) 10 and 19 in rodents) and the early postnatal days (PND) (27). An accurate regulation of their activation is critical for the development of a proper immune response and for maintaining brain homeostasis. Indeed, as recently demonstrated, abnormal microglia activity can influence cortical neurogenesis (28), neuronal migration, axonal growth $(29,30)$, and synaptic pruning (31). These events that occur during the fetal and the early postnatal period are critical for the development of a functional brain architecture and their alterations can generate "pre-symptomatic signatures" correlated to the manifestation of neurological disease later in life as suggested by the neuro-archeological hypothesis (32). Abnormal microglia activation can also negatively affect myelinization (27). In order to better understand the relation between microglia and myelinization, it is important to consider the developmental stages of myelinization. The process is defined by initial migration and proliferation of oligodendrocyte precursors followed by their differentiation first into pre-oligodendrocytes (pre-OL) and then into mature oligodendrocytes (33). In particular, pre-OL showed higher intrinsic vulnerability to environmental insults and exposure of the brain to free radical or to excitotoxic molecules dramatically affect their maturation and differentiation (34). Abnormal microglial activation is the third factor affecting preOL maturation, a pivotal player in the context of WMI $(27,34)$ (Figure 1). Thus considering this background, the early modulation of the microglia activity could represent a valid therapeutic option for the treatment of brain injury in prematurity and to prevent the printing of the "pre-symptomatic signature" of neurological disease.

\section{EARLY OVEREXPOSURE TO GLUCOCORTICOSTEROIDS (GCs): IMPACT ON NEUROINFLAMMATION AND OXYTOCIN PRODUCTION}

The release of GCs is regulated by the hypothalamic-pituitaryadrenal axis (HPA) (35). HPA axis activation results in the release of corticotropin releasing factor (CRF) from the hypothalamic paraventricular nucleus (PVN) in the portal vessel system, inducing the secretion of adrenocorticotropic hormone (ACTH) from the pituitary that in turn stimulates the release of GCs from the adrenal gland.

Glucocorticosteroids, classically described as anti-inflammatory and immunosuppressive agents, have also displayed proinflammatory actions. Indeed, studies conducted in humans and in rodents showed that chronic exposure to stress or to high levels of GCs potentiate the inflammatory response both at central and peripheral levels (36-38).

The pro-inflammatory effects of GCs are long lasting and early life stress is able to shift the immune response toward a pro-inflammatory phenotype later in life (39-41) with a direct effect on microglia immunoreactivity and maturation (42-45). Concerning the latter point, the study (42) showed that exposure to prenatal stress between ED 10 and 20 affects microglia maturation by inducing a reduction of immature microglia in the corpus callosum and an increase in ramified microglia in other brain regions at PND 1. More recently, two different studies

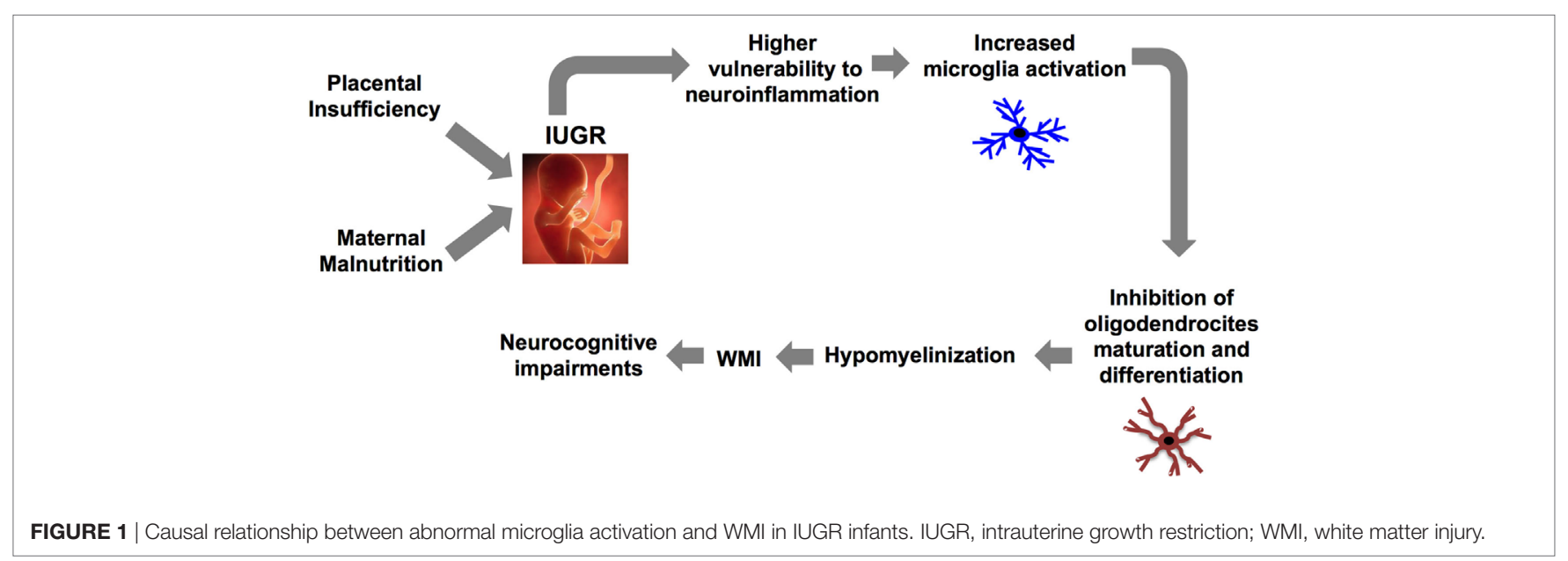


demonstrated that exposure to maternal separation (MS) (43) or to prenatal stress (44) increase the activation of microglia cells in the hippocampus at PND15 and the number of activated microglia in the hippocampus and in the cortex of adult animals, respectively. In the same study (44) the authors showed, through an in vitro approach, that microglia isolated from prenatal stressed animals is more amoeboid and releases higher levels of pro-inflammatory cytokines. In addition, as reported in Ref. (45), exposure to prenatal stress is able to shift the hippocampal microglia morphology toward an activated phenotype not only in basal condition, but also in response to LPS stimulation in adults.

The mechanisms responsible for these effects are not yet well understood, however, an important role could be exerted by nuclear GCs receptors (GRs). GRs regulate the HPA activity by means of negative feedback (46) and the anti-inflammatory effects of GCs are promoted by the formation of a GC/GR complex (47). As previously reviewed, hippocampal GRs undergo epigenetic regulation of their expression that is influenced by early parental care (48). Interestingly, two human studies reported an increase in GR methylation in leukocytes and mononuclear cord blood cells in adults (49) and infants (50) exposed to childhood adversity, respectively. Moreover, a recent study evidenced a relation between GR methylation and inflammation at the central level (51). Rats exposed to MS showed, as adults, a higher methylation of hippocampal GR receptor that is linked to an increase in hippocampal astrocytes inflammatory response following sevoflurane administration. Interestingly, these effects can be reversed by treatment with an epigenetic regulator (51).

Because microglia are the resident immune cells of the brain, we hypothesize that stress or high levels of GCs can induce epigenetic modification of GRs on microglia too. The change in GR expression could, therefore, shift the microglia response toward the pro-inflammatory phenotype observed in premature infants and in animal models of IUGR. In this context, defining strategies to prevent exposure of the developing brain to high pro-inflammatory levels of GCs acquire greater importance.

Oxytocin is a neuropeptide released by the PVN and by the supraoptic nucleus of the hypothalamus. Studies conducted in rodents and in humans showed the existence of a bidirectional relation between the HPA axis and OTX: exposure to stress induced an increase in OTX plasma levels (52-54), while OTX administration counterbalanced axis activation reducing GCs release (55-59). The details of this inhibitory action were clarified via pharmacological approaches in several studies. In particular, intra-cerebroventricular administration of OTX induces a reduction in CRF mRNA levels in the PVN in response to stress $(55,57)$ and a reduction in ACTH and corticosterone plasma levels both in the basal condition (58) and in response to stress $(55,56,58)$ (Figure 2). This proven ability to modulate the GCs release supports the hypothesis of

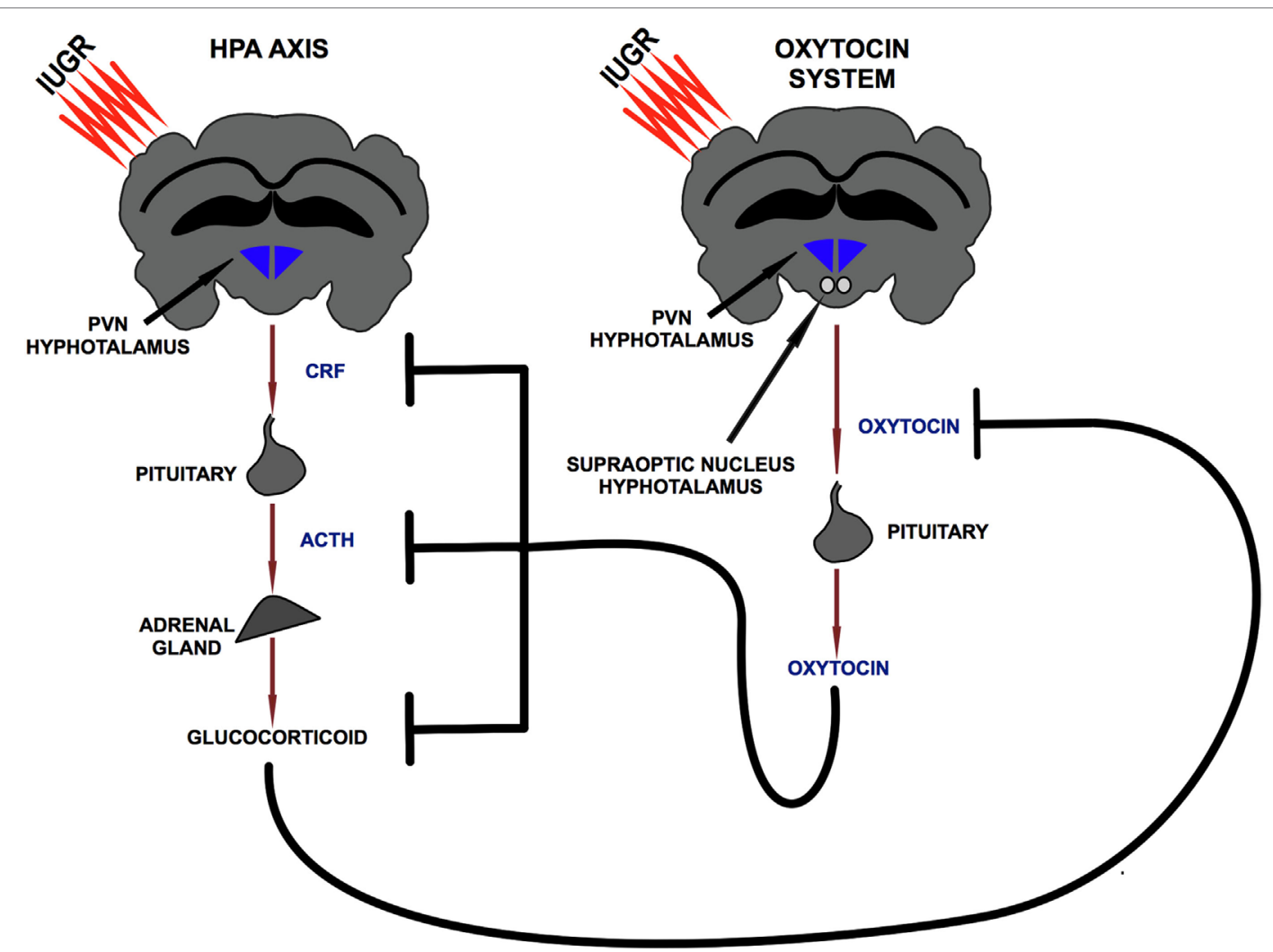

FIGURE 2 | Bidirectional relationship between hypothalamic-pituitary-adrenal axis and oxytocin system. PVN, paraventricular nucleus; CRF, corticotropin releasing factor; $\mathrm{ACTH}$, adrenocorticotropic hormone. 
a functional interaction between the OTX system, HPA axis, and immune system. In this mutual communication between the three endogenous systems, OTX could exert an indirect anti-inflammatory action through the control of HPA axis activation. Therefore, during the early phase of life, OTX could have an important role to prevent the exposure of the brain to high and pro-inflammatory doses of GCs.

\section{RELATION BETWEEN OTX AND THE IMMUNE SYSTEM: EVIDENCES OF AN ANTI-INFLAMMATORY EFFECT}

Oxytocin known for its role in labor and lactation is generally used in clinical practice for the induction and augmentation of labor (60). However, recent investigations in animals evidenced a pivotal role of OTX in the regulation of a central inflammatory response (61-63). The anti-inflammatory action in the brain was described for the first time in an animal model of brain stroke (MCAO) in combination with social housing and social isolation protocols (61). Social environment is associated with a reduction in incidence, mortality, and morbidity of stroke (61, 64). Housing in a social environment increases the synthesis of OTX mRNA in the hypothalamus and interestingly, this increase mediates the neuroprotective effects of the social environment (61). Indeed, intracerebral administration of an OTX receptor (OTXR) antagonist neutralized the neuroprotective effects of the social environment, whereas the administration of OTX to socially isolated animals before induction of cerebral arterial occlusion improved stroke outcome reducing infarct size, oxidative stress, stroke-induced gliosis, and neuroinflammation (61). In addition, a recent in vivo study demonstrated that intracerebral administration of OTX reduced pro-inflammatory gene expression in the hippocampus of adult animals exposed to MS (62).

Studies aimed at clarifying the cellular target of this antiinflammatory action pointed out a role for the OTX system in the regulation of microglia reactivity both in vivo and in vitro (61, 63). Regarding the in vivo evidence, the study (63) demonstrated that intranasal administration of OTX to adult mice reduced microglia activation and pro-inflammatory cytokine expression induced by an LPS injection. In addition, in the same study the authors demonstrated that OXT is able to reduce the LPS-induced activation both in primary microglia and in microglia cell lines (63). Similar results have been reported in microglia cells purified from socially isolated animals and stimulated in vitro with LPS (61).

The biological action of OTX is linked to the activation of OTXR, a selective seven transmembrane Gq/Gi-coupled receptor (65) expressed both in astrocytes and in microglia $(61,63)$. Exposure of microglia cells to inflammatory stimulus induced a time-dependent increase in OTXR expression (63) suggesting that the OTX system is an inducible system that undergoes a dynamic regulation to respond to the requests of an immune challenge. The molecular bases of neuroprotective action of OTX are not well known and modulation of the downstream ERK/MAPK pathway in microglia was reported only in one study (63). In addition, other molecular effectors of OTXR (e.g., NFkB, eukaryotic elongation factor 2) could mediate the observed effect. Finally, because microglia also express receptors for glutamate and other important neurotransmitter (e.g., GABA, Acetylcholine) (66), the existence of a functional crosstalk between OTXR and other neurotransmitter receptors cannot be ruled out.

\section{EFFECTS OF OTX ON THE NEONATAL BRAIN AND "GABA SWITCH"}

The early phase of life represents a period of maximum plasticity for the brain. Indeed, during this time it undergoes morphological changes that are fundamental for the development of correct excitatory and inhibitory neuronal circuits. An abnormal balance between excitatory and inhibitory transmission have been proposed as a causal factor for the occurrence of neurodevelopmental disorders (e.g., autism) (67) and in this context an interesting role is mediated by GABA $(68,69)$. GABA, the main inhibitory neurotransmitter in adults, exerts an excitatory effect in the immature brain switching transiently to an inhibitory action during delivery, and permanently during the first postnatal week $(70,71)$. The peculiar $\mathrm{Cl}^{-}$homeostasis that characterizes the immature brain is at the base of GABA excitatory action (67). Indeed, immature neurons express on their membrane high levels of $\mathrm{Cl}^{-}$importer $\mathrm{NKCC} 1$, and low levels of $\mathrm{Cl}^{-}$exporter $\mathrm{KCC} 2$ with a consequent increase in $\mathrm{Cl}^{-}$intracellular concentration (67). In presence of this ionic gradient, activation of the GABA receptor $\left(\mathrm{GABA}_{\mathrm{A}} \mathrm{R}\right)$ induces an efflux of $\mathrm{Cl}^{-}$and the consequent generation of an excitatory membrane depolarization (67).

Alteration of GABAergic signaling is reported in several neurodevelopmental diseases, such as autism (69) and Fragile $\mathrm{X}(68,72)$. Therefore, the understanding of the mechanisms underlying the GABA function in the immature brain acquires greater importance.

Oxytocin is a key player for the biphasic transition of GABA and during delivery a main role is exerted by maternal OTX. Parturition is indeed associated with a massive release of OTX (73) that easily crosses the placenta and reaches the fetus (74). Combining the electrophysiological approach with in vivo administration of an OTXR antagonist to pregnant rats, Tyzio et al. elegantly demonstrated that maternal OTX is necessary and sufficient to promote GABA switch (70) and that the inhibition of this OTX-mediated transition induces in the offspring an autisticlike phenotype (69). The modulation of NKCC1 activity is at the base of OTX-mediated GABA switch during delivery (70) and, as observed for OTX, the administration of an NKCC1 antagonist to pregnant rats reverts the abnormal electrophysiological phenotype in two animal models of autism (69). Concerning the role of OTX in the postnatal GABA switch, a recent research highlighted the involvement of the KCC2 transporter (67). Indeed, mutant OTXR ${ }^{-/}$mice showed delayed GABA switch associated with reduced KCC2 hippocampal expression. On the contrary, wild type animals showed in the early postnatal period correct GABA transition and an increase in KCC2 expression that are promoted by activation of OTXR and of its downstream pathway 
Gq/protein kinase C. Interestingly, this OTXR-mediated modulation of KCC2 expression is time dependent and restricts to an early time point (67). This observation further highlighted the pivotal role of OTX in the first phase of life and supports the hypothesis of OTX as a novel neuroprotective agent in the immature brain. Indeed, a precocious treatment of preterm infants with OTX could represent a valid therapeutic strategy to ensure correct brain development and perhaps reduce the risk of developing neurodevelopmental disorders later in life.

\section{EFFECTS OF OTX ON THE NEONATAL BRAIN AND THE ROLE OF MODULATION OF MATERNAL BEHAVIOR}

Oxytocin is an important hormone for the regulation of maternal behavior (75-80) and this interaction was first reported by Pedereson and Fahrbach $(75,76)$. Indeed, the authors demonstrated that intracerebral administration of OTX to virgin female rats reduced the latency to develop maternal care in response to exposure to forest pups $(75,76)$. In agreement with these results, intracerebral administration of an OTXR antagonist reduced maternal behavior and canceled the differences between high maternal care (High LG-ABN) and low maternal care (Low LG-ABN) mothers (78). High LG-ABN is associated with a higher level of OTX (77) and of OTXR in the medial preoptic area, a hypothalamic area important for the regulation of maternal care $(78,79)$. In humans, the increase in plasma OTX between the first and the second trimester of pregnancy is predictive of motherinfant bonding (81) and higher plasmatic and salivary levels of OTX are observed in mothers with high affectionate contact (80).

Maternal attachment is the first form of social interaction and its quality and quantity influence the behavioral and neuroendocrine outcomes of the organisms. Indeed, human studies reported that a low quantity and quality of maternal care are associated with a higher risk to develop adult psychopathy (82) and to worse cognitive performances later in life (83). In agreement with these human results, animal studies clearly demonstrated that rats reared by low LG-ABN showed, as adults, impaired cognitive performances $(84,85)$ increase in anxiogenic behavior (86) and fearfulness (87). Moreover, low LG-ABN showed hyperactivity of the HPA axis in response to stress (88).

Considering the ability of OTX to modulate the insurgence of maternal care and the positive effects of high levels of maternal behavior, it is possible to suggest a functional interaction between OTX and maternal care. Therefore, OTX could exert an indirect neuroprotective effect through modulation of maternal care.

\section{CONCLUSION}

Intrauterine growth restriction is recognized to be an important public health problem and growth-restricted infants present an increased risk to develop cognitive and behavioral alterations later in life. As evidenced by clinical studies these increased risks are significantly correlated to the development of gray and white matter injury including altered neural circuitry. Preclinical and clinical studies have demonstrated that neuroinflammation, associated with abnormal microglia reactivity, is a causal factor for the development of WMI. Therefore, the modulation of inflammation could represent a valid therapeutic strategy for the treatment of brain injury in preterm infants. In this context, the neuropeptide OTX can exert a pivotal role due to its ability to modulate the immune system and shift its activity toward an anti-inflammatory phenotype. The studies discussed in this review demonstrate that this anti-inflammatory effect is exerted through the regulation of microglia activation. However, the beneficial effects of OTX are not only related to the modulation of neuroinflammation, but also to the development of correct neural circuitry. Indeed, its action is necessary to regulate the "GABA switch" and the proper balance between excitatory and inhibitory transmission whose alterations have been linked to the occurrence of neurodevelopmental disorders. Finally, the positive effects of OTX can not only be confined to a direct action on the immature brain. Indeed, OTX is an important regulator of maternal behavior and alterations of maternal care are correlated to the insurgence of behavioral and neuroendocrine alterations later in life. Thus, it is possible to suppose that the modulation of maternal care is one of the mechanisms at the base of OTXmediated neuroprotection. In conclusion, the data summarized here supports the hypothesis of OTX as a potential neuroprotective agent in the developing brain.

\section{METHODS}

The present review summarizes clinical and preclinical data about causal relations between inflammation and neonatal brain injury, and recapitulates experimental evidences hypothesizing OTX as a novel anti-inflammatory and neuroprotective agent in the immature brain. A literature search was performed in December 2017-January 2018 using the PubMed library in English. No restriction of year and authors were applied and review papers were used as references only for the general concepts. The literature search relating to the pre-clinical studies was restricted to research conducted in rats and mice. Only papers that satisfied the following criteria were included: pertinence to the subject, presence of control groups, and clear descriptions of experimental procedures.

\section{AUTHOR CONTRIBUTIONS}

$\mathrm{MZ}$ and JM did the literature review. All the authors collectively analyzed articles selected in this review paper. $\mathrm{MZ}$, JM, and OB wrote the manuscript. All the authors revised and approved final version of the manuscript.

\section{ACKNOWLEDGMENTS}

We thank Audrey Toulotte-Aebi for editing the manuscript draft.

\section{FUNDING}

This study was supported by INSERM, "Agence Nationale de la Recherche" (ANR), and by "La Fondation Paralysie Cérébrale," France. 


\section{REFERENCES}

1. Jarvis S, Glinianaia SV, Torrioli M-GG, Platt M-JJ, Miceli M, Jouk P-SS, et al. Cerebral palsy and intrauterine growth in single births: European collaborative study. Lancet (2003) 362(9390):1106-11.

2. Regev RH, Lusky A, Dolfin T, Litmanovitz I, Arnon S, Reichman B, et al. Excess mortality and morbidity among small-for-gestational-age premature infants: a population-based study. J Pediatr (2003) 143(2):186-91. doi:10.1067/ S0022-3476(03)00181-1

3. Nardozza LMM, Caetano ACR, Zamarian ACP, Mazzola JB, Silva CP, Marçal VMG, et al. Fetal growth restriction: current knowledge. Arch Gynecol Obstet (2017) 295(5):1061-77. doi:10.1007/s00404-017-4341-9

4. Katz J, Lee AC, Kozuki N, Lawn JE, Cousens S, Blencowe H, et al. Mortality risk in preterm and small-for-gestational-age infants in low-income and middle-income countries: a pooled country analysis. Lancet (2013) 382(9890):417-25. doi:10.1016/S0140-6736(13)60993-9

5. Geva R, Eshel R, Leitner Y, Fattal-Valevski A, Harel S. Memory functions of children born with asymmetric intrauterine growth restriction. Brain Res (2006) 1117(1):186-94. doi:10.1016/j.brainres.2006.08.004

6. Korzeniewski SJ, Allred EN, Joseph RM, Heeren T, Kuban KCK, O'Shea TM, et al. Neurodevelopment at age 10 years of children born $<28$ weeks with fetal growth restriction. Pediatrics (2017) 140(5):e20170697. doi:10.1542/ peds.2017-0697

7. Dubois J, Benders M, Borradori-Tolsa C, Cachia A, Lazeyras F, Ha-Vinh Leuchter R, et al. Primary cortical folding in the human newborn: an early marker of later functional development. Brain (2008) 131(Pt 8):2028-41. doi:10.1093/brain/awn137

8. Egaña-Ugrinovic G, Sanz-Cortes M, Figueras F, Couve-Perez C, Gratacós E. Fetal MRI insular cortical morphometry and its association with neurobehavior in late-onset small-for-gestational-age fetuses. Ultrasound Obstet Gynecol (2014) 44(3):322-9. doi:10.1002/uog.13360

9. Lodygensky GA, Seghier ML, Warfield SK, Tolsa CB, Sizonenko S, Lazeyras F, et al. Intrauterine growth restriction affects the preterm infant's hippocampus. Pediatr Res (2008) 63(4):438-43. doi:10.1203/PDR.0b013e318165c005

10. Padilla N, Junqué C, Figueras F, Sanz-Cortes M, Bargalló N, Arranz A, et al. Differential vulnerability of gray matter and white matter to intrauterine growth restriction in preterm infants at 12 months corrected age. Brain Res (2014) 1545:1-11. doi:10.1016/j.brainres.2013.12.007

11. Tolsa CB, Zimine S, Warfield SK, Freschi M, Rossignol AS, Lazeyras F, et al. Early alteration of structural and functional brain development in premature infants born with intrauterine growth restriction. Pediatr Res (2004) 56(1):132-8. doi:10.1203/01.PDR.0000128983.54614.7E

12. Batalle D, Eixarch E, Figueras F, Muñoz-Moreno E, Bargallo N, Illa M, et al. Altered small-world topology of structural brain networks in infants with intrauterine growth restriction and its association with later neurodevelopmental outcome. Neuroimage (2012) 60(2):1352-66. doi:10.1016/j. neuroimage.2012.01.059

13. Fischi-Gómez E, Vasung L, Meskaldji D-E, Lazeyras F, Borradori-Tolsa C, Hagmann P, et al. Structural brain connectivity in school-age preterm infants provides evidence for impaired networks relevant for higher order cognitive skills and social cognition. Cereb Cortex (2015) 25(9):2793-805. doi:10.1093/ cercor/bhu073

14. Jacobsson B, Ahlin K, Francis A, Hagberg G, Hagberg H, Gardosi J. Cerebral palsy and restricted growth status at birth: population-based case-control study. BJOG (2008) 115(10):1250-5. doi:10.1111/j.1471-0528.2008.01827.x

15. Blair E, Stanley F. Intrauterine growth and spastic cerebral palsy. Am J Obstet Gynecol (1990) 162(1):229-37. doi:10.1016/0002-9378(90)90856-3

16. Jacobsson B, Hagberg G. Antenatal risk factors for cerebral palsy. Best Pract Res Clin Obstet Gynaecol (2004) 18(3):425-36. doi:10.1016/j.bpobgyn.2004. 02.011

17. MacLennan AH, Thompson SC, Gecz J. Cerebral palsy: causes, pathways, and the role of genetic variants. Am J Obstet Gynecol (2015) 213(6):779-88. doi:10.1016/j.ajog.2015.05.034

18. McIntyre S, Blair E, Badawi N, Keogh J, Nelson KB. Antecedents of cerebral palsy and perinatal death in term and late preterm singletons. Obstet Gynecol (2013) 122(4):869-77. doi:10.1097/AOG.0b013e3182a265ab

19. Wixey JA, Chand KK, Colditz PB, Bjorkman ST. Review: neuroinflammation in intrauterine growth restriction. Placenta (2017) 54:117-24. doi:10.1016/j. placenta.2016.11.012
20. Leviton A, Dammann O, Durum SK. The adaptive immune response in neonatal cerebral white matter damage. Ann Neurol (2005) 58(6):821-8. doi:10.1002/ana.20662

21. Rezaie P, Dean A. Periventricular leukomalacia, inflammation and white matter lesions within the developing nervous system. Neuropathology (2002) 22(3):106-32. doi:10.1046/j.1440-1789.2002.00438.x

22. Pham H, Duy AP, Pansiot J, Bollen B, Gallego J, Charriaut-Marlangue C, et al. Impact of inhaled nitric oxide on white matter damage in growth-restricted neonatal rats. Pediatr Res (2015) 77(4):563-9. doi:10.1038/pr.2015.4

23. Olivier P, Baud O, Bouslama M, Evrard P, Gressens P, Verney C. Moderate growth restriction: deleterious and protective effects on white matter damage. Neurobiol Dis (2007) 26(1):253-63. doi:10.1016/j.nbd.2007.01.001

24. Olivier P, Baud O, Evrard P, Gressens P, Verney C. Prenatal ischemia and white matter damage in rats. JNeuropathol Exp Neurol (2005) 64(11):998-1006. doi:10.1097/01.jnen.0000187052.81889.57

25. Campbell LR, Pang Y, Ojeda NB, Zheng B, Rhodes PG, Alexander BT. Intracerebral lipopolysaccharide induces neuroinflammatory change and augmented brain injury in growth-restricted neonatal rats. Pediatr Res (2012) 71(6):645-52. doi:10.1038/pr.2012.26

26. Liddelow SA, Guttenplan KA, Clarke LE, Bennett FC, Bohlen CJ, Schirmer L, et al. Neurotoxic reactive astrocytes are induced by activated microglia. Nature (2017) 541(7638):481-7. doi:10.1038/nature21029

27. Hanisch U-K, Kettenmann H. Microglia: active sensor and versatile effector cells in the normal and pathologic brain. Nat Neurosci (2007) 10(11):1387-94. doi:10.1038/nn1997

28. Cunningham CL, Martinez-Cerdeno V, Noctor SC. Microglia regulate the number of neural precursor cells in the developing cerebral cortex. J Neurosci (2013) 33(10):4216-33. doi:10.1523/JNEUROSCI.3441-12.2013

29. Squarzoni P, Oller G, Hoeffel G, Pont-Lezica L, Rostaing P, Low D, et al. Microglia modulate wiring of the embryonic forebrain. Cell Rep (2014) 8(5):1271-9. doi:10.1016/j.celrep.2014.07.042

30. Pont-Lezica L, Beumer W, Colasse S, Drexhage H, Versnel M, Bessis A. Microglia shape corpus callosum axon tract fasciculation: functional impact of prenatal inflammation. Eur J Neurosci (2014) 39(10):1551-7. doi:10.1111/ ejn.12508

31. Kim H-J, Cho M-H, Shim WH, Kim JK, Jeon E-Y, Kim D-H, et al. Deficient autophagy in microglia impairs synaptic pruning and causes social behavioral defects. Mol Psychiatry (2017) 22(11):1576-84. doi:10.1038/mp.2016.103

32. Ben-Ari Y. Neuro-archaeology: pre-symptomatic architecture and signature of neurological disorders. Trends Neurosci (2008) 31(12):626-36. doi:10.1016/j. tins.2008.09.002

33. van Tilborg E, de Theije CGM, van Hal M, Wagenaar N, de Vries LS, Benders MJ, et al. Origin and dynamics of oligodendrocytes in the developing brain: implications for perinatal white matter injury. Glia (2018) 66(2):221-38. doi:10.1002/glia.23256

34. Volpe JJ, Kinney HC, Jensen FE, Rosenberg PA. Reprint of "The developing oligodendrocyte: key cellular target in brain injury in the premature infant". Int J Dev Neurosci (2011) 29(6):565-82. doi:10.1016/j.ijdevneu.2011.07.008

35. Den Boon FS, Sarabdjitsingh RA. Circadian and ultradian patterns of HPA-axis activity in rodents: significance for brain functionality. Best Pract Res Clin Endocrinol Metab (2017) 31(5):445-57. doi:10.1016/j.beem.2017. 09.001

36. Loram LC, Taylor FR, Strand KA, Frank MG, Sholar P, Harrison JA, et al. Prior exposure to glucocorticoids potentiates lipopolysaccharide induced mechanical allodynia and spinal neuroinflammation. Brain Behav Immun (2011) 25(7):1408-15. doi:10.1016/j.bbi.2011.04.013

37. Johnson JD, O'connor KA, Deak T, Stark M, Watkins LR, Maier SF. Prior stressor exposure sensitizes LPS-induced cytokine production. Brain Behav Immun (2002) 16(4):461-76. doi:10.1006/brbi.2001.0638

38. Yeager MP, Rassias AJ, Pioli PA, Beach ML, Wardwell K, Collins JE, et al. Pretreatment with stress cortisol enhances the human systemic inflammatory response to bacterial endotoxin. Crit Care Med (2009) 37(10):2727-32. doi:10.1097/CCM.0b013e3181a592b3

39. Meagher MW, Sieve AN, Johnson RR, Satterlee D, Belyavskyi M, Mi W, et al. Neonatal maternal separation alters immune, endocrine, and behavioral responses to acute Theiler's virus infection in adult mice. Behav Genet (2010) 40(2):233-49. doi:10.1007/s10519-010-9333-5

40. Vanbesien-Mailliot CCAA, Wolowczuk I, Mairesse J, Viltart O, Delacre M, Khalife J, et al. Prenatal stress has pro-inflammatory consequences on the 
immune system in adult rats. Psychoneuroendocrinology (2007) 32(2):114-24. doi:10.1016/j.psyneuen.2006.11.005

41. Avitsur R, Hunzeker J, Sheridan JF. Role of early stress in the individual differences in host response to viral infection. Brain Behav Immun (2006) 20(4):339-48. doi:10.1016/j.bbi.2005.09.006

42. Gómez-González B, Escobar A. Prenatal stress alters microglial development and distribution in postnatal rat brain. Acta Neuropathol (2010) 119(3):303-15. doi:10.1007/s00401-009-0590-4

43. Roque A, Ochoa-Zarzosa A, Torner L. Maternal separation activates microglial cells and induces an inflammatory response in the hippocampus of male rat pups, independently of hypothalamic and peripheral cytokine levels. Brain Behav Immun (2016) 55:39-48. doi:10.1016/j.bbi.2015.09.017

44. Ślusarczyk J, Trojan E, Głombik K, Budziszewska B, Kubera M, Lasoń W, et al. Prenatal stress is a vulnerability factor for altered morphology and biological activity of microglia cells. Front Cell Neurosci (2015) 9:82. doi:10.3389/ fncel.2015.00082

45. Diz-Chaves Y, Pernía O, Carrero P, Garcia-Segura LM. Prenatal stress causes alterations in the morphology of microglia and the inflammatory response of the hippocampus of adult female mice. J Neuroinflammation (2012) 9:1. doi:10.1186/1742-2094-9-71

46. Herman JP, McKlveen JM, Solomon MB, Carvalho-Netto E, Myers B. Neural regulation of the stress response: glucocorticoid feedback mechanisms. Biol Res (2012) 45(4):292-8.

47. Sorrells SF, Sapolsky RM. An inflammatory review of glucocorticoid actions in the CNS. Brain Behav Immun (2007) 21(3):259-72. doi:10.1016/j. bbi.2006.11.006

48. Zhang TY, Labonté B, Wen XL, Turecki G, Meaney MJ. Epigenetic mechanisms for the early environmental regulation of hippocampal glucocorticoid receptor gene expression in rodents and humans. Neuropsychopharmacology (2013) 38(1):111-23. doi:10.1038/npp.2012.149

49. Tyrka AR, Price LH, Marsit C, Walters OC, Carpenter LL. Childhood adversity and epigenetic modulation of the leukocyte glucocorticoid receptor: preliminary findings in healthy adults. PLoS One (2012) 7(1):e30148. doi:10.1371/ journal.pone. 0030148

50. Oberlander TF, Weinberg J, Papsdorf M, Grunau R, Misri S, Devlin AM. Prenatal exposure to maternal depression, neonatal methylation of human glucocorticoid receptor gene (NR3C1) and infant cortisol stress responses. Epigenetics (2008) 3(2):97-106. doi:10.4161/epi.3.2.6034

51. Zhu Y, Wang Y, Yao R, Hao T, Cao J, Huang H, et al. Enhanced neuroinflammation mediated by DNA methylation of the glucocorticoid receptor triggers cognitive dysfunction after sevoflurane anesthesia in adult rats subjected to maternal separation during the neonatal period. J Neuroinflammation (2017) 14(1):6. doi:10.1186/s12974-016-0782-5

52. Yoshida M, Takayanagi Y, Onaka T. The medial amygdala-medullary PrRPsynthesizing neuron pathway mediates neuroendocrine responses to contextual conditioned fear in male rodents. Endocrinology (2014) 155(8):2996-3004. doi:10.1210/en.2013-1411

53. Minhas S, Liu C, Galdamez J, So VM, Romeo RD. Stress-induced oxytocin release and oxytocin cell number and size in prepubertal and adult male and female rats. Gen Comp Endocrinol (2016) 234:103-9. doi:10.1016/j.ygcen. 2016.03.014

54. Sanders G, Freilicher J, Lightman SL. Psychological stress of exposure to uncontrollable noise increases plasma oxytocin in high emotionality women. Psychoneuroendocrinology (1990) 15(1):47-58. doi:10.1016/0306-4530(90) 90046-C

55. Windle RJ, Kershaw YM, Shanks N, Wood SA, Lightman SL, Ingram CD. Oxytocin attenuates stress-induced c-fos mRNA expression in specific forebrain regions associated with modulation of hypothalamo-pituitary-adrenal activity. J Neurosci (2004) 24(12):2974-82. doi:10.1523/JNEUROSCI.343203.2004

56. Windle RJ, Shanks N, Lightman SL, Ingram CD. Central oxytocin administration reduces stress-induced corticosterone release and anxiety behavior in rats. Endocrinology (1997) 138(7):2829-34. doi:10.1210/endo.138.7.5255

57. Jurek B, Slattery DA, Hiraoka Y, Liu Y, Nishimori K, Aguilera G, et al. Oxytocin regulates stress-induced Crf gene transcription through CREB-regulated transcription coactivator 3. J Neurosci (2015) 35(35):12248-60. doi:10.1523/ JNEUROSCI.1345-14.2015

58. Neumann ID, Wigger A, Torner L, Holsboer F, Landgraf R. Brain oxytocin inhibits basal and stress-induced activity of the hypothalamo-pituitary-adrenal axis in male and female rats: partial action within the paraventricular nucleus. J Neuroendocrinol(2001) 12(3):235-43. doi:10.1046/j.1365-2826.2000.00442.x

59. Ditzen B, Schaer M, Gabriel B, Bodenmann G, Ehlert U, Heinrichs M. Intranasal oxytocin increases positive communication and reduces cortisol levels during couple conflict. Biol Psychiatry (2009) 65(9):728-31. doi:10.1016/j.biopsych.2008.10.011

60. Page K, McCool WF, Guidera M. Examination of the pharmacology of oxytocin and clinical guidelines for use in labor. J Midwifery Womens Health (2017) 62(4):425-33. doi:10.1111/jmwh.12610

61. Karelina K, Stuller KA, Jarrett B, Zhang N, Wells J, Norman GJ, et al. Oxytocin mediates social neuroprotection after cerebral ischemia. Stroke (2011) 42(12):3606-11. doi:10.1161/STROKEAHA.111.628008

62. Amini-Khoei H, Mohammadi-Asl A, Amiri S, Hosseini M-J, Momeny M, Hassanipour M, et al. Oxytocin mitigated the depressive-like behaviors of maternal separation stress through modulating mitochondrial function and neuroinflammation. Prog Neuropsychopharmacol Biol Psychiatry (2017) 76(169-178):2017. doi:10.1016/j.pnpbp.2017.02.022

63. Yuan L, Liu S, Bai X, Gao Y, Liu G, Wang X, et al. Oxytocin inhibits lipopolysaccharide-induced inflammation in microglial cells and attenuates microglial activation in lipopolysaccharide-treated mice. J Neuroinflammation (2016) 13(1):77. doi:10.1186/s12974-016-0541-7

64. Weil ZM, Norman GJ, Barker JM, Su AJ, Nelson RJ, Devries AC. Social isolation potentiates cell death and inflammatory responses after global ischemia. Mol Psychiatry (2008) 13(10):913-5. doi:10.1038/mp.2008.70

65. Busnelli M, Chini B. Molecular basis of oxytocin receptor signalling in the brain: what we know and what we need to know. Curr Top Behav Neurosci (2017). doi:10.1007/7854_2017_6

66. Liu H, Leak RK, Hu X. Neurotransmitter receptors on microglia. Stroke Vasc Neurol (2016) 1(2):52-8. doi:10.1136/svn-2016-000012

67. Leonzino M, Busnelli M, Antonucci F, Verderio C, Mazzanti M, Chini B. The timing of the excitatory-to-inhibitory GABA switch is regulated by the oxytocin receptor via KCC2. Cell Rep (2016) 15(1):96-103. doi:10.1016/j. celrep.2016.03.013

68. He Q, Nomura T, Xu J, Contractor A. The developmental switch in GABA polarity is delayed in fragile X mice. JNeurosci (2014) 34(2):446-50. doi:10.1523/JNEUROSCI.4447-13.2014

69. Tyzio R, Nardou R, Ferrari DC, Tsintsadze T, Shahrokhi A, Eftekhari S, et al. Oxytocin-mediated GABA inhibition during delivery attenuates autism pathogenesis in rodent offspring. Science (2014) 343(6171):675-9. doi:10.1126/science. 1247190

70. Tyzio R, Cossart R, Khalilov I, Minlebaev M, Hübner CA, Represa A, et al. Maternal oxytocin triggers a transient inhibitory switch in GABA signaling in the fetal brain during delivery. Science (2006) 314(5806):1788-92. doi:10.1126/ science. 1133212

71. Valeeva G, Valiullina F, Khazipov R. Excitatory actions of GABA in the intact neonatal rodent hippocampus in vitro. Front Cell Neurosci (2013) 7:20. doi: $10.3389 /$ fncel.2013.00020

72. Curia G, Papouin T, Séguéla P, Avoli M. Downregulation of tonic GABAergic inhibition in a mouse model of fragile X syndrome. Cereb Cortex (2009) 19(7):1515-20. doi:10.1093/cercor/bhn159

73. Gimpl G, Fahrenholz F. The oxytocin receptor system: structure, function, and regulation. Physiol Rev (2001) 81(2):629-83. doi:10.1152/ physrev.2001.81.2.629

74. MalekA,BlannE,MattisonDR.Humanplacentaltransportofoxytocin.J Matern Fetal Med (1996) 5(5):245-55. doi:10.1002/(SICI)1520-6661(199609/10) 5:5<245::AID-MFM3>3.0.CO;2-H

75. Pedersen C, Ascher J, Monroe Y, Prange A. Oxytocin induces maternal behavior in virgin female rats. Science (1982) 216(4546):648-50. doi:10.1126/ science.7071605

76. Fahrbach SE, Morrell JI, Pfaff DW. Oxytocin induction of short-latency maternal behavior in nulliparous, estrogen-primed female rats. Horm Behav (1984) 18(3):267-86. doi:10.1016/0018-506X(84)90016-3

77. Shahrokh DK, Zhang T-Y, Diorio J, Gratton A, Meaney MJ. Oxytocindopamine interactions mediate variations in maternal behavior in the rat. Endocrinology (2010) 151(5):2276-86. doi:10.1210/en.2009-1271

78. Champagne F, Diorio J, Sharma S, Meaney MJ. Naturally occurring variations in maternal behavior in the rat are associated with differences in estrogen-inducible central oxytocin receptors. Proc Natl Acad Sci U S A (2001) 98(22):12736-41. doi:10.1073/pnas.221224598 
79. Francis DD, Champagne FC, Meaney MJ. Variations in maternal behaviour are associated withdifferencesinoxytocinreceptorlevelsintherat.J Neuroendocrinol (2000) 12(12):1145-8. doi:10.1046/j.1365-2826.2000.00599.x

80. Feldman R, Gordon I, Schneiderman I, Weisman O, Zagoory-Sharon O. Natural variations in maternal and paternal care are associated with systematic changes in oxytocin following parent-infant contact. Psychoneuroendocrinology (2010) 35:1133-41. doi:10.1016/j.psyneuen.2010.01.013

81. Feldman R, Weller A, Zagoory-Sharon O, Levine A. Evidence for a neuroendocrinological foundation of human affiliation. Psychol Sci (2007) 18(11):965-70. doi:10.1111/j.1467-9280.2007.02010.x

82. Gao Y, Raine A, Chan F, Venables PH, Mednick SA. Early maternal and paternal bonding, childhood physical abuse and adult psychopathic personality. Psychol Med (2010) 40(6):1007-16. doi:10.1017/S0033291709991279

83. Sylva K, Stein A, Leach P, Barnes J, Malmberg L-E. FCCC-team. Effects of early child-care on cognition, language, and task-related behaviours at 18 months: an English study. Br J Dev Psychol (2011) 29(Pt 1):18-45. doi:10.1348/02615 1010X533229

84. Bagot RC, Zhang T-Y, Wen X, Nguyen TTT, Nguyen H-B, Diorio J, et al. Variations in postnatal maternal care and the epigenetic regulation of metabotropic glutamate receptor 1 expression and hippocampal function in the rat. Proc Natl Acad Sci U S A (2012) 109(Suppl):17200-7. doi:10.1073/ pnas.1204599109

85. Liu D, Diorio J, Day JC, Francis DD, Meaney MJ. Maternal care, hippocampal synaptogenesis and cognitive development inrats. Nat Neurosci (2000) 3(8):799-806. doi:10.1038/77702
86. Caldji C, Tannenbaum B, Sharma S, Francis D, Plotsky PM, Meaney MJ. Maternal care during infancy regulates the development of neural systems mediating the expression of fearfulness in the rat. Proc Natl Acad Sci U S A (1998) 95(9):5335-40. doi:10.1073/pnas.95.9.5335

87. Menard JL, Champagne DL, Meaney MJP. Variations of maternal care differentially influence "fear" reactivity and regional patterns of cFos immunoreactivity in response to the shock-probe burying test. Neuroscience (2004) 129(2):297-308. doi:10.1016/j.neuroscience.2004.08.009

88. Liu D, Diorio J, Tannenbaum B, Caldji C, Francis D, Freedman A, et al. Maternal care, hippocampal glucocorticoid receptors, and hypothalamic-pituitary-adrenal responses to stress. Science (1997) 277(5332):1659-62. doi:10.1126/science.277.5332.1659

Conflict of Interest Statement: The authors declare that the research was conducted in the absence of any commercial or financial relationships that could be construed as a potential conflict of interest.

Copyright (C) 2018 Zinni, Colella, Batista Novais, Baud and Mairesse. This is an open-access article distributed under the terms of the Creative Commons Attribution License (CC BY). The use, distribution or reproduction in other forums is permitted, provided the original author(s) and the copyright owner are credited and that the original publication in this journal is cited, in accordance with accepted academic practice. No use, distribution or reproduction is permitted which does not comply with these terms. 